\title{
Research on the Elements of Excellent Chinese Teachers Based on the Differences of Learners' Chinese Proficiency
}

\author{
Qiqing Huang \\ (Yunnan Chinese Language and Culture College, Yunnan Normal University, Kunming, China \\ 650500)
}

147627946@qq.com

\begin{abstract}
Keywords: Chinese Proficiency; Excellent Chinese Teacher; Personality element; Teaching element.
\end{abstract}

Abstract. Through two surveys before and after, this paper conducts statistics and analyses on the personality elements and teaching elements of excellent Chinese teachers expected by different Chinese language learners. The research results show that the expectations of the learners of different Chinese language levels on the elements of excellent Chinese teachers show a relatively distinct level or continuity. This also reflects the level of learning and life needs of learners of different Chinese levels in the target language environment. The article puts forward some suggestions for the application of this research in teacher teaching and teacher education.

As we all know, international Chinese teachers have always been one of the three major bottlenecks restricting the rapid development of international Chinese education. In recent years, nearly 400 universities in China have opened undergraduate programs in Chinese international education, and 110 universities have established master's programs in Chinese international education. The number of international Chinese teachers has become large, and the construction of international Chinese teachers has achieved results. This is worthy of recognition. How to build an excellent team of Chinese teachers under the premise of ensuring the number of teachers is a new issue in the international Chinese education community. This is mainly because "The overseas Confucius Institute and the Confucius Classroom, the Chinese Department of overseas universities, the universities that recruit foreign students in China, and the private education institutions are increasingly demanding excellent Chinese teachers." (Xiliang Cui,2013) In addition, the awareness of professional awareness, professional awareness and subject development of international Chinese teachers are constantly increasing. (Qiqing Huang,2017) Becoming an excellent Chinese teacher is also the dream of many young teachers.

So, what is an excellent Chinese teacher? What are the components of a good Chinese teacher? There are three commonly used criteria in the academic community when studying excellent language teachers: One is the excellent language teacher confirmed by the student, the second is the excellent teacher confirmed by the peer or the leader, and the third is the excellent teacher determined by the scale test. Whether it is "student-centered" or "study-centered", learners are the most authentic evaluators of excellent Chinese teachers. However, different Chinese learners have different expectations for excellent Chinese teachers. It is undoubtedly a correct and refined research path to explore the constituent elements of excellent Chinese teachers from the individual differences of learners. This paper investigates the expectation elements of different learners for excellent Chinese teachers from the perspective of learners' Chinese proficiency. This research helps us to scientifically understand the connotation of excellent Chinese teachers, and to implement targeted or differentiated Chinese teaching based on the learner's Chinese proficiency.

\section{Investigation Process}

Before the questionnaire was produced, we surveyed 126 Chinese learners from 23 different countries with the title "The Best Chinese Teacher in My Heart". From the 621 elements of the survey, 99 elements of excellent Chinese teachers were combined and analyzed, including 24 teacher personality elements and 75 teacher teaching elements. We used these 99 elements to 
survey 305 international students studying Chinese at Yunnan Normal University, Yunnan University, Yunnan University of Finance and Economics, Yunnan Minzu University, and Kunming University of Science and Technology. A total of 305 questionnaires is distributed and 295 valid questionnaires were used. It is $96.7 \%$. There are some questionnaires with incomplete information and data. For the treatment of these missing values, we conduct statistical analysis based on the principle of faithfulness to the original data. Therefore, in the following description of the information of survey object, the sum of the various types of statistical data may not be 295 . The surveyed targets 118 male students, 173 female students, 4 missing information; 98 European and American students, 192 Asian students, 2 South Americans, 2 Africans, and 1 Oceania; judging from the subjective level of the respondents' subjective assessment, there are 95 primary level, 142 intermediate level, 53 senior level, and 5 missing information. The primary level is mainly the entry-level and junior-level students of the five universities. The intermediate level is mainly the intermediate and individual advanced students. However, the advanced level is mainly for advanced students studying in the advanced class and part of the graduate students majoring in Chinese international education at Yunnan Normal University.

\section{Excellent Chinese Teacher Personality Elements Based on Learners' Chinese Proficiency}

We divide the level of Chinese subjectively selected by learners into three stages: primary, intermediate and advanced. After analyzing the correlation between teachers' personality elements, we found four elements of Chinese level and teachers' patience $(\mathrm{P}=0.003)$, kindness $(\mathrm{P}=0.046)$, enthusiasm $(\mathrm{P}=0.001)$ and sincerity $(\mathrm{P}=0.006)$. There is a significant positive correlation. There is a significant negative correlation with the three elements of "good-looking $(\mathrm{P}=0.032)$ ", "cute $(\mathrm{P}=0.012)$ " and "young $(\mathrm{P}=0.042)$ ", that is the higher the learner's Chinese level, the more patient, cordial, and sincere. Enthusiastic teacher. But expectations for teachers' appearances are getting lower and lower. So what are the significant differences in the personality elements of excellent Chinese teachers that are expected between Chinese learners of different levels? After one-way analysis of variance, we obtained the following results:

Table 1 Comparison of teacher personality factors expected by junior, intermediate and senior level learners

\begin{tabular}{|l|l|l|}
\hline \multirow{2}{*}{ Nationality } & \multicolumn{2}{|c|}{ Mesult } \\
\cline { 2 - 3 } & \multicolumn{1}{|c|}{ Former } & \multicolumn{1}{c|}{ Latter } \\
\hline $\begin{array}{l}\text { Primary \& } \\
\text { Intermediate }\end{array}$ & & $\begin{array}{l}\text { Kind }(\mathrm{P}=0.028) \text {, friendly }(\mathrm{P}=0.023) \text {, enthusiasm }(\mathrm{P}=0.002), \\
\text { generous }(\mathrm{P}=0.041) \text {, sincere }(\mathrm{P}=0.040) \text {, open mind }(\mathrm{P}=0.033)\end{array}$ \\
\hline $\begin{array}{l}\text { Primary } \\
\text { \&Senior }\end{array}$ & $\begin{array}{l}\text { Good-looking }(\mathrm{P}=0.019), \text { cute } \\
(\mathrm{P}=0.008), \text { young }(\mathrm{P}=0.035)\end{array}$ & Patience $(\mathrm{P}=0.000)$, enthusiasm $(\mathrm{P}=0.004)$, sincerity $(\mathrm{P}=0.008)$ \\
\hline $\begin{array}{l}\text { Intermediate } \\
\text { \& senior }\end{array}$ & $\begin{array}{l}\mathrm{G} \text { Good-looking }(\mathrm{P}=0.028), \text { cute } \\
(\mathrm{P}=0.032), \text { moderate }(\mathrm{P}=0.039)\end{array}$ & Patience $(\mathrm{P}=0.001)$ \\
\hline
\end{tabular}

Significantly correlated at the .01 level (both sides).

Significant correlation at 0.05 level (both sides).

The table shows that, in contrast, Chinese learners at the primary and intermediate levels remarkably expect the teacher's appearance. For example, "good-looking" and "cute", but the former is more looking forward to "young" teachers, and the latter is more looking forward to "moderate" teachers. Compared with junior level learners, intermediate level Chinese learners are looking forward to teachers who are friendly, generous, sincere and open-minded. This shows a desire to communicate with the teacher "unforced" or "accessible". Compared with junior level learners, both senior and intermediate level learners are looking forward to enthusiastic and sincere teachers. Compared with junior middle school Chinese level learners, advanced Chinese learners also significantly expect patient teachers. In short, it may be understood that the expectation of teachers from the primary level to the advanced level is from the appearance factor to the continuum of positive patient communication. Because the expectations of teachers of different 
levels of Chinese language are just as deep as the depths, from acquaintance to mutual understanding to the communicative process of dare to make demands. It reflects the depth of the relationship between teachers and students formed or expected between learners and teachers of different levels of Chinese.

\section{Excellent Chinese Teacher Teaching Elements Based on Learners' Chinese Proficiency}

It can be seen from the above statistics and analysis that the expectation of teachers' personality elements by different Chinese level learners shows obvious hierarchy or continuity. So, is the expectation of learners of different Chinese language levels to the teaching elements of excellent Chinese teachers the same? We first analyze the correlation between the Chinese level of the respondents and the teaching elements of the teachers. The results are as follows:

Table 2 Correlation between Chinese Proficiency and Teaching Elements of Excellent Chinese

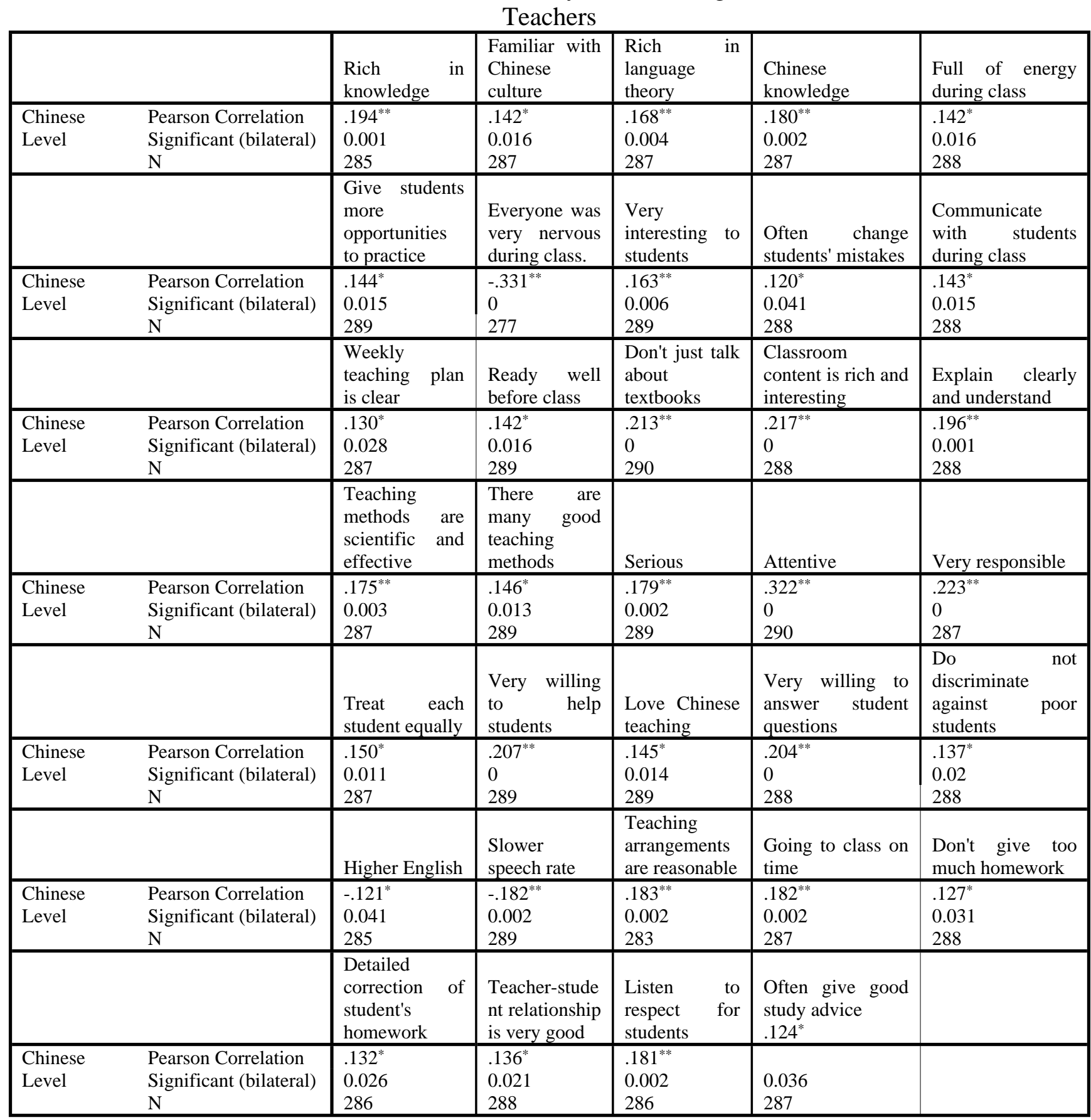

Significantly correlated at the .01 level (both sides).

Significant correlation at 0.05 level (both sides). 
Excellent Chinese teachers with positive correlation with Chinese proficiency are more diverse. It mainly includes: basic knowledge of teachers, such as "rich Chinese knowledge", "very rich knowledge of teachers", "familiar with Chinese culture" and "rich knowledge of linguistics"; Teachers' teaching attitudes, such as "very responsible", "serious", "intentional", "love of Chinese teaching work", "prepared well before class", "detailed correction of students' homework", etc.; Teaching ability and methods, such as "clear and easy to understand" "often change students' mistakes" "more opportunities for students to practice" "scientific and effective teaching methods" "multiple communication with students during class" "there are many good teaching methods" Students are very interested". Good teacher-student relationship, such as "often giving good study advice" "Good teacher-student relationship" "Listening to respect students' opinions" "Very willing to help students" "Very willing to answer student questions" "Do not discriminate against students who are not good at learning" "Equal treatment of each student", etc.; Teaching plans, such as "on time and class" "study is very reasonable" "every week's teaching plan is clear", etc.; teaching content, such as "don't just talk about textbooks" and "classroom content is rich and interesting." Others have a "sportsmanship in class" and "do not give too much homework" in the homework. This shows that the higher the level of Chinese, the higher the expectations of teachers' basic knowledge, teaching ability, teaching attitude, teacher-student relationship, teaching plan, and teaching content. This is one of the reasons why higher-level Chinese teaching has higher requirements for teachers.

We conducted a one-way analysis of variance on the expectations of the Chinese language teachers at the junior, intermediate and senior levels of Chinese language. The homogeneity test of variance shows that the following 32 teaching elements do not have the homogeneity of variance: "Intention ( $\mathrm{P}=0.000)$ " "Common PPT class $(\mathrm{P}=0.000)$ " "There are many good teaching methods $(\mathrm{P}=0.000)$ " "Classroom content is rich and interesting $(\mathrm{P}=0.001)$ "'"The book is clearly organized $(\mathrm{P}=0.002)$ " "Responsible $(\mathrm{P}=0.002)$ " "Equal to each student $(\mathrm{P}=0.003)$ "'The teaching method is scientific and effective $(\mathrm{P}=0.005)$ " "Chinese knowledge is rich $(\mathrm{P}=0.005)$ " "Slow speed $(\mathrm{P}=0.005)$ " "Very willing to answer student questions $(\mathrm{P}=0.006)$ "' Can control bad emotions $(\mathrm{P}=0.006)$ " "Don't just talk about textbooks $(\mathrm{P}=0.006)$ " "Teacher's lesson is very interesting $(\mathrm{P}=0.008)$ " "Familiar with China's profile and culture $(\mathrm{P}=0.013)$ " Explain clearly and understandable $(\mathrm{P}=0.013)$ ""Practical teaching arrangement $(\mathrm{P}=0.019)$ "" More opportunities for students to practice $(\mathrm{P}=0.019)$ ""Putonghua is very standard $(\mathrm{P}=0.021)$ ""Detailed correction of student's homework ( $\mathrm{P}=0.021)$ " "Always let students watch movies $(\mathrm{P}=0.023)$ "'Don't compare with other classes $(\mathrm{P}=0.026)$ " "Love Chinese teaching work $(\mathrm{P}=0.028)$ " "Large voice $(\mathrm{P}=0.034)$ " "Very willing to help students $(\mathrm{P}=0.035)$ " "Class time Communicate more with students $(\mathrm{P}=0.039)$ " "Caring for students' understanding ( $\mathrm{P}=0.039)$ " "Listen to respect students' opinions $(\mathrm{P}=0.040)$ " "Let's go to class on time $(\mathrm{P}=0.040)$ " "Create context to let students practice ( $\mathrm{P}=0.044)$ "'Frequently changed students' errors $(\mathrm{P}=0.044)$ "“"Creating context allows students to practice $(\mathrm{P}=0.044)$ " "Frequently changing students' errors $(\mathrm{P}=0.044)$ " "The teacher is very knowledgeable $(\mathrm{P}=0.045)$ ". In the statistics of these teaching elements that do not have the homogeneity of variance, the factor analysis under the condition of "no assumption of variance" is still adopted. The specific results are as follows: 
Table 3 Comparison of teachers' teaching elements expected by junior, intermediate and senior level learners

\begin{tabular}{|c|c|c|}
\hline \multirow{2}{*}{$\begin{array}{l}\text { Result } \\
\text { Nationalit }\end{array}$} & \multicolumn{2}{|c|}{ Mean comparison result (significant difference) } \\
\hline & Former & Latter \\
\hline $\begin{array}{l}\text { Primary \& } \\
\text { Intermediate }\end{array}$ & $\begin{array}{l}\text { The classroom sounds a little } \\
\text { louder }(\mathrm{P}=0.019) \text {, the English } \\
\text { level is higher }(\mathrm{P}=0.032) \text {, and } \\
\text { the speech rate is slower } \\
(\mathrm{P}=0.007) \text {. }\end{array}$ & $\begin{array}{l}\text { Rich Chinese knowledge }(\mathrm{P}=0.011) \text {, very responsible } \\
(\mathrm{P}=0.048) \text {, scientific and effective teaching method }(\mathrm{P}=0.003) \text {, } \\
\text { serious }(\mathrm{P}=0.007) \text {, intention ( } \mathrm{P}=0) \text {, rich and interesting } \\
\text { classroom content }(\mathrm{P}=0.037)) \text {, the teacher is rich in knowledge } \\
(\mathrm{P}=0.015) \text {, treats each student equally }(\mathrm{P}=0.047) \text {, Mandarin is } \\
\text { very standard }(\mathrm{P}=0.029) \text {, loves Chinese teaching }(\mathrm{P}=0.045) \text {, and } \\
\text { has a rich expression in class }(\mathrm{P}=0.031) \text { During the class, } \\
\text { everyone was very nervous }(\mathrm{P}=0.014) \text {, they communicated with } \\
\text { students during class }(\mathrm{P}=0.014) \text {, they were full of spirits during } \\
\text { class }(\mathrm{P}=0.024) \text {, and there were many good teaching methods } \\
(\mathrm{P}=0.041) \text {. }\end{array}$ \\
\hline $\begin{array}{l}\text { Primary \& } \\
\text { Senior }\end{array}$ & $\begin{array}{l}\text { Everyone was very nervous } \\
\text { during class }(\mathrm{P}=0.000) \text {, and } \\
\text { the speech rate was slower } \\
(\mathrm{P}=0.012)\end{array}$ & 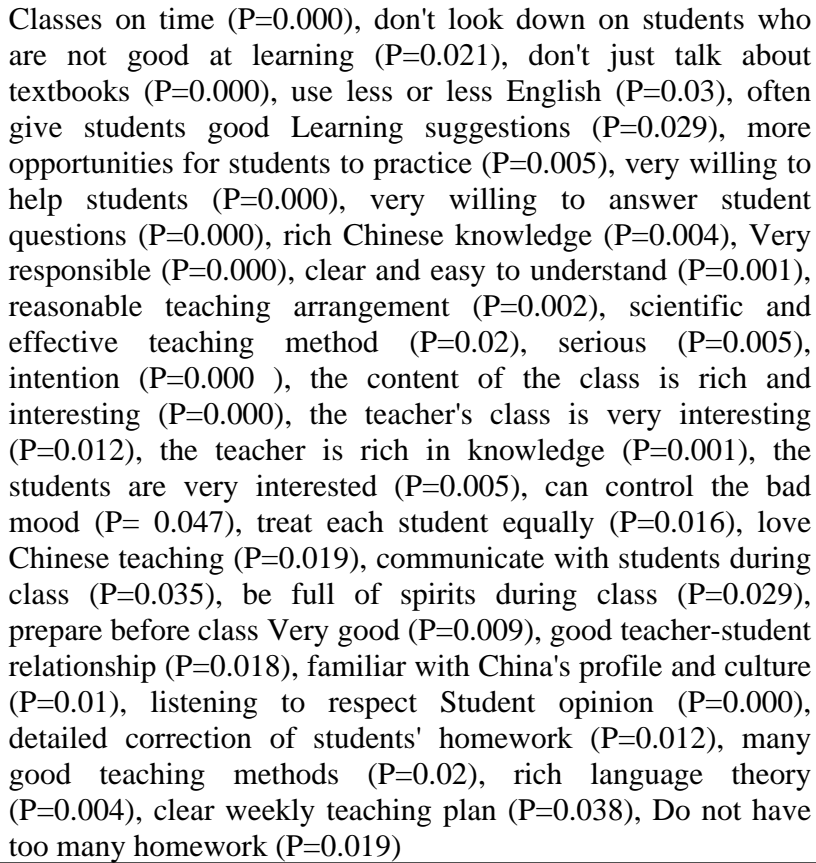 \\
\hline $\begin{array}{l}\text { Intermediate } \\
\& \text { senior }\end{array}$ & $\begin{array}{l}\text { Everyone was very nervous } \\
\text { during class }(\mathrm{P}=0.000)\end{array}$ & $\begin{array}{l}\text { Classes on time }(\mathrm{P}=0.001) \text {, not only on textbooks }(\mathrm{P}=0.001) \text {, no } \\
\text { or less English }(\mathrm{P}=0.032) \text {, often encourage students to be } \\
\text { praised }(\mathrm{P}=0.039) \text {, create context for students to practice }(\mathrm{P} \\
=0.037) \text {, more opportunities for students to practice }(\mathrm{P}=0.014) \text {, } \\
\text { more questions ( } \mathrm{P}=0.022) \text {, very willing to help students } \\
(\mathrm{P}=0.004) \text {, very willing to answer student questions }(\mathrm{P}=0.002) \text {, } \\
\text { very negative Responsibility ( } \mathrm{P}=0.003) \text {, clear explanation } \\
(\mathrm{P}=0.038) \text {, reasonable teaching arrangement }(\mathrm{P}=0.035) \text {, } \\
\text { intention ( } \mathrm{P}=0.001) \text {, rich and interesting classroom content } \\
(\mathrm{P}=0.026) \text {, teacher's lesson ( } \mathrm{P}=0.001) \text {, prepared well before } \\
\text { class }(\mathrm{P}=0.022) \text {, listened to respect for students' opinions } \\
(\mathrm{P}=0.000) \text {, chat with students in class ( } \mathrm{P}=0.002) \text {, detailed } \\
\text { correction of students' work }(\mathrm{P}=0.033) \text {, homework Too much } \\
(\mathrm{P}=0.036)\end{array}$ \\
\hline
\end{tabular}

As can be seen from the statistics in the above table, the primary Chinese level learners do not expect much from the intermediate and senior Chinese level learners. They have a significant expectation of the teacher's loud voice, senior English level, and slower speaking speed than the intermediate level. These elements are some of their basic requirements for understandable input. Primary Chinese level learners are relative to intermediate Chinese level learners. Intermediate Chinese level learners and relatively advanced Chinese level learners are all looking forward to the "very nervous during class" element. This element is not so much an expectation of the teacher's teaching elements, but rather an identity of the learner's own learning state. Perhaps the respondents did not use this article as an element of a good Chinese teacher when filling out the questionnaire. It is an expression of anxiety in a state of nervousness and anxiety in the process of learning. This 
element reflects the state of anxiety of junior and intermediate Chinese level learners in the process of learning Chinese.

Intermediate Chinese level learners are expected to look forward to the following elements in relation to junior Chinese level learners:

Teaching attitude. They look forward to teachers who are responsible, conscientious, dedicated, and passionate about Chinese teaching.

Teacher knowledge quality. They look forward to knowledgeable Chinese teachers.

Teaching method. They look forward to a rich, scientific, effective, and multi-disciplinary approach to teaching.

Teaching aspect. They are looking forward to the teacher who is "rich in class" and "full of energy in class."

In addition, they also look forward to the "classroom content is rich and interesting" and "equal treatment of each student" teachers.

Intermediate Chinese level learners have more requirements for teachers' teaching than junior Chinese level learners, and they are also relatively high. It shows that the intermediate Chinese level learners hope to study Chinese with the help of excellent Chinese teachers, actively improve Chinese, and have a certain psychological pursuit of teaching interest and fairness. It is important to note that Chinese level learners at this stage have no obvious requirement for the language of instruction relative to junior level Chinese learners. This shows that Chinese learners at this stage have basically reached the level of being able to understand the target language, that is Chinese.

Senior Chinese level learners have raised higher and more specific requirements than intermediate Chinese level learners. They mainly look forward to the following aspects:

Teaching attitude. In addition to the expectation of "very responsible" and "intentional" as well as intermediate Chinese level learners, they also put forward specific requirements for the two teaching links, namely, the attitude of preparing for the lesson and reviewing the work, that is "well-prepared before class" and "detailed correction of students' homework."

Teaching ability and method. Senior Chinese level learners have specific and explicit requirements for teachers' ability to "clear and understand" and other practice methods. The latter includes "creating context for students to practice" "to give more opportunities for students to practice" and "to ask more about the content of the text". These teaching elements on teaching ability and practice methods are just the necessary conditions for improving the efficiency of Chinese teaching, conforming to the second language acquisition mechanism (intelligible input and second language acquisition in use) and effectively promoting second language acquisition.

Teacher-student relationship. Compared with the situation that intermediate Chinese level learners have no expectation of teacher-student relationship, senior Chinese level learners have made clear requirements for teacher-student relationship. Such as "often encourage and praise students" "very willing to help students" "very willing to answer student questions" "listen to respect the opinions of students" "student often chat with students" and so on. It can be seen from these factors that higher level Chinese learners are expected to receive encouragement, praise, help and respect from teachers.

Teaching plan. Senior Chinese level learners have clear requirements for the teaching plan of teachers. Such as "add and drop class on time" and "reasonable teaching arrangements. "It shows that senior Chinese level learners have strong learning planning and initiative.

Teaching content. Like the intermediate Chinese level learners, they are expecting "classroom content is rich and interesting". But comparing with the intermediate Chinese level learners, they are more clearly looking forward to the "Do not just talk about the textbook" element. It shows the expectations of senior Chinese level learners for enriching teaching content and their dislike of excessive dependence on teaching materials.

Teaching language. Compared with junior Chinese proficiency learners, they are expecting "higher English proficiency" and intermediate Chinese proficiency learners without any expectation of teaching language. Senior Chinese learners are obviously expecting teachers to "do not use or use less English. "This shows that as the level of target language increases, language learners rely on 
the process of changing from the medium of instruction to the language of instruction. Obviously, this process is also related to the acquisition mechanism of the second language. The revised grade model of Kroll \& Stewart (1994) argues that in the initial stage of acquisition, the second language is connected to the concept through a vocabulary, also known as lexical connection. In the middle and advanced stages of acquisition, the second language vocabulary is gradually connected directly to the second language concept, also known as the concept connection. The native language or the language already mastered has a conceptual adjustment effect in the process of second language acquisition. However, as the level of the second language increases, the learner will gradually learn to use the second language without getting rid of the language or having the help of the language.

From the above comparative analysis, it can be seen that with the improvement of the target language level, the language learners' requirements for language teachers are getting higher and higher, more and more specific, and also getting closer to learners' second language acquisition and the inner needs of cultural communication. In addition, it can be seen that the learner's current level of Chinese determines the content and extent of the learner's expectations for the teaching elements of excellent Chinese teachers. The expectations of learners of different Chinese language levels for the teaching elements of excellent Chinese teachers reflect a relatively significant level or continuity.

\section{Conclusion and Enlightenment}

This paper examines the components of excellent Chinese teachers from the perspectives of learners' Chinese learning duration and Chinese proficiency. The research conclusions prove that Chinese learners with different Chinese proficiency have different and significant expectations for the individual elements and teaching elements of excellent Chinese teachers. These different distinctive expectation elements show a distinct feature, that is the lower the level of Chinese, the higher the requirements for the teacher's appearance elements and teaching language elements; the higher the level of Chinese, the higher the expectation of the teacher's basic quality, teaching ability, teaching methods, teaching content, teaching attitude, teaching consciousness (including cross-cultural communication awareness, practice awareness, teaching fairness awareness, professional awareness, etc.). The requirements for teaching languages, including teaching mediums, are getting lower and lower. The expectation content of the learner's personality elements and teaching elements by different Chinese level learners reflects a distinct level or continuity.

From "The higher the level of Chinese learners, the higher the comprehensive requirements for teachers", it can be seen that the process of learners learning Chinese is actually a cross-cultural communication process that meets their own needs. That is to say, the learner's learning is not only the learning of the act itself, but also the problem in the classroom space. They also have the basic pursuit of the universal meaning of human beings. The use of Maslow's hierarchy of needs allows us to have a clearer understanding of the statistical results of this study. Maslow needs hierarchical theory to be divided into lack of needs and growth needs. The former is also called basic needs, including physiological needs, security needs, attribution needs, self-esteem needs, and the latter mainly refers to self-realization needs. The satisfaction of "necessity needs" depends to a large extent on others and the environment, while "growth needs" can be largely independent of others and the environment. The higher the level of Chinese, the higher the pursuit of teachers' knowledge, teaching, care, fairness and respect, which means that the learner's Chinese learning process is also a pursuit of satisfying physiological needs, security needs, and attribution needs in the target language culture. Self-esteem requires even the self-realization of the intercultural communication process required.

In combination with the above conclusions, we recommend that as an international Chinese teacher, especially an excellent international Chinese teacher. First of all, it should be understood that learners of different levels of Chinese are different in their requirements for teachers. Secondly, in the process of international Chinese education, students can be taught differently at different levels of Chinese-level learners according to the expectations of middle- and high-level Chinese level learners. For junior learners, you can use English, the learner's native language or other 
mediums to teach, and you should slow down. On the contrary, for senior Chinese level learners, you should use less or less English, learner's mother tongue or other medium language, but use Chinese as much as possible for teaching. For example, for beginner Chinese level learners, we should do our best to do a good job in language teaching and strive to improve the junior communicative competence of learners. For senior Chinese language learners, we should carry out more in-depth cross-cultural communication and humanistic care for Chinese learners while doing a good job in language teaching. Thirdly, primary and intermediate Chinese level learners have a higher degree of anxiety, and classroom learning often has a nervous state of anxiety, which is a normal reflection. While doing a good job in language teaching, international Chinese teachers should also give more help and care to junior and intermediate level Chinese learners.

In addition, some learners have high expectations for the appearance of Chinese teachers such as "young", "good-looking", "cute" and "dressing". This is an indisputable fact. Qi Hua et al. (2013) found that at the first class, the three groups of international students firstly noticed the teacher's voice, followed by appearance, again posture, and finally, costume. The Chinese teacher's clothing, appearance, voice and other object language will affect $12.50 \%$ to $54.76 \%$ of international students in different countries. This also indirectly confirms the conclusions of some of the respondents in this study who are concerned about the appearance of the teacher and the dress. The teacher's appearance and dressing are not the main factors affecting Chinese teaching. However, in teaching, it is not uncommon for the non-verbal communication problems such as dress etiquette to cause unhappy dissatisfaction between teachers and students and even to resist conflicts. We do not advocate excessive consideration of the appearance and dressing factors in the selection and training of teachers, and even oppose the appearance of people. However, in the process of international Chinese teacher education or training, the fact that Chinese learners are expecting the external image of teachers should be considered and the trained teachers should be given soft guidance in the external image or put forward uniform requirements in dressing.

\section{References}

[1] Xiliang Cui, On the Academic Conscientiousness of TCSL Teachers. Chinese Teaching in the World,2013,(4).

[2] Qiqing Huang, The Retrospect and Prospect of Studies on International Chinese Education Teachers for Thirty Years. Teaching And Research On Chinese As A Foreign Language, 2017,(2).

[3] Kroll J \& Stewart E, Category interference in translation and picture naming: Evidence for asymmetric connections between bilingual memory representations. Journal of Memory and Language, 1994,(2) .

[4] Hua Qi et al, Influence of TCF Teachers' Clothes and Ornaments on Classroom Teaching: An Investigation among International Students with Multi-cultural Backgrounds. Teaching And Research On Chinese As A Foreign Language,2013,(2).

[5] Abraham H. Maslow, Motivation and Personality, third ed. Jinsheng $\mathrm{Xu}$ et al, translation. Beijing: China Renmin University Press(CRUP),2007. 